\title{
ORIENTAÇÕES CURRICULARES PARA A EDUCAÇÃO DE JOVENS E ADULTOS: ENFOQUES E CONTEXTOS NACIONAL E MUNICIPAL
}

\author{
CURRICULUM GUIDELINES FOR YOUNG AND ADULT EDUCATION: \\ APPROCHES AND CONTEXTS
}

\author{
Lenir Keller $^{1}$ e Elsbeth Léia Spode Becker ${ }^{2}$
}

\section{RESUMO}

O artigo tem por objetivo trazer para o debate as orientações curriculares para a Educação de Jovens e Adultos, considerando o cenário nacional e o local, a Rede Municipal de Ensino de Santa Maria - RS. Para tanto, as discussões envolvem o conceito de currículo e as implicações no contexto escolar, as orientações curriculares nacional e municipal, os questionamentos sobre a composição da identidade curricular da modalidade a proposta de integração à Educação Profissional. Por meio de uma pesquisa documental são arroladas as diretrizes curriculares e pareceres para a modalidade e, recorrendo à pesquisa bibliográfica, são consideradas as abordagens de Sacristán (2000, 2013), Arroyo (2005, 2011), Oliveira (2007) e Ramos (2010 sobre o tema. Por fim, exploram-se algumas pistas para reflexão e ressignificação do currículo da modalidade e pôde-se inferir que a atual conjuntura educacional da EJA, extremamente fragilizada, necessita discutir o currículo escolar com a efetiva contribuição de alunos e professores e, assim, conduzir à solidez da modalidade como espaço de exercício de direitos e de emancipação.

Palavras-chave: currículo, identidade, contexto escolar.

\section{ABSTRACT}

The paper aims to bring to the debate the curricular guidelines for Young and Adult Education, considering the national and local scenario, the Educational System of Santa Maria - RS. Therefore, the discussions involve the concept of curriculum and the implications in the school context, national and municipal curriculum guidelines, questions about the composition of the curricular identity of the modality and the proposal for integration with Professional Education. Through documentary research, the curriculum guidelines and legal advice for the modality are listed and, using bibliographic research, the approaches of Sacristan (2000, 2013), Arroyo (2005, 2011), Oliveira (2007) and Ramos (2010) are considered about the subject. Finally, some clues for reflection and re-signification of the modality curriculum are explored and it was possible to infer that the current educational situation of Young and Adult Education, extremely fragile, needs to discuss the school curriculum with the effective contribution of students and teachers. Thus, it can lead to the solidification of the modality as a space for the exercise of rights and emancipation.

Keywords: curriculum; identity; school context.

\footnotetext{
1 Professora da Rede Municipal de Ensino de Santa Maria e mestranda no Mestrado em Ensino de Humanidades e Linguagens - MEHL, da Universidade Franciscana - UFN. E-mail: lenirkeller@yahoo.com.br

2 Professora Adjunta III - Área das Ciências Humanas - Universidade Franciscana. E-mail: elsbeth.geo@gmail.com
} 


\section{INTRODUÇÃO}

Diante da proposta de discorrer sobre as orientações curriculares para a Educação de Jovens e Adultos (EJA) e suas implicações na constituição da identidade da modalidade, sob diferentes enfoques e contextos, retoma-se que políticas públicas são "[...] um conjunto de programas e projetos que parte da sociedade propõe para a sociedade como um todo, configurando-se a orientação política de um determinado governo que assume e desempenha as funções de Estado por um determinado período" (HÖFLING, 2001, p. 30). As políticas públicas educacionais abarcam os diversos espaços formativos e devem promover a garantia do direito universal à educação de qualidade e o exercício da cidadania. Considera-se a "[...] a natureza complexa e controversa da política educacional [...]”, bem como "[...] a necessidade de se articularem os processos macro e micro na análise de políticas educacionais" (MAINARDES, 2006, p. 49).

No Brasil, as políticas públicas são frequentemente alteradas ou extintas, "[...] marcadas hegemonicamente pela lógica da descontinuidade, por carência de planejamento de longo prazo que evidenciasse políticas de Estado em detrimento de políticas conjunturais de governo" (DOURADO, 2007, p. 925). Portanto, em decorrência da alternância dos partidos políticos no poder, há a troca projetos de governo. As consequências são sentidas pela descontinuidade das metas e ausência de programas consistentes, que resultam em intervenções superficiais. Nesse cenário, as políticas públicas deveriam ser planejadas e implementadas para atendimento das demandas da sociedade, num movimento dinâmico, compondo um ciclo contínuo constituído por três contextos principais: da influência, da produção de texto e o da prática (MAINARDES, 2006), os quais se inter-relacionam em permanentes processos de disputas e resistências.

Resgatando a trajetória da EJA no Brasil, o contexto da influência foi perpassado pelas agendas internacionais em favor da alfabetização de adultos, os movimentos sociais e as mudanças político-sociais instaladas com o processo de redemocratização do país, sendo esse período decisivo para a mudança na formulação e definição de políticas para EJA, de uma visão compensatória para emancipadora (BRASIL, 2000). O contexto do texto se estabeleceu nos significados advindos do contexto da influência, os quais se materializam na formulação da legislação, no caso, a própria Constituição Federal, a Lei de Diretrizes e Bases da Educação Nacional nº 9394/96, demais pareceres e orientações curriculares nos âmbitos federal e municipal. No contexto da prática, as formulações se desdobram em ações, passíveis às interpretações e reformulações dos sujeitos envolvidos (alunos, pais, professores, instituições), produzindo efeitos e consequências muitas vezes diversos do planejado face às múltiplas e complexas ações e reações dos segmentos sociais, compondo o quarto contexto: dos resultados ou efeitos, pois “[...] as políticas deveriam ser analisadas em termos do seu impacto e das interações com desigualdades existentes" (MAINARDES, 2006, p. 54). 
Decorridas quase duas décadas a contar da implantação da EJA no país e no município de Santa Maria/RS, em 2001, questões sobre a organização curricular têm sido objeto de discussões e pesquisas. Há convergência entre estudos e autores sobre a EJA que apontam inconsistências no próprio sistema educacional como uma proposta curricular inadequada e desatualizada. Daí a importância das avaliações das políticas públicas educacionais no sentido de incorporar o retorno do contexto dos efeitos para continuidade, adaptação, transformação ou ruptura das políticas educacionais em andamento, realimentando o ciclo das políticas configurando-se, então, o contexto de estratégia política que “[...] envolve a identificação de um conjunto de atividades sociais e políticas que seriam necessárias para lidar com as desigualdades criadas ou reproduzidas pela política investigada" (MAINARDES, 2006, p 55).

A metodologia foi embasada no estado da arte a partir das políticas públicas educacionais para a EJA e trazer o foco para as orientações curriculares na modalidade, na perspectiva da pesquisa qualitativa, cujos procedimentos técnicos utilizados envolvem a pesquisa bibliográfica e a pesquisa documental, adotada como complementar, pois a pesquisa bibliográfica tem como base materiais já elaborados, constituídos, principalmente livros e artigos científicos, visando colocar o pesquisador em contato com o que já se produziu e se registrou a respeito do tema de pesquisa. Já a pesquisa documental se vale de materiais que não receberam tratamento analítico, como leis, pareceres, dados estatísticos (GIL, 2017).

Desta forma, torna-se relevante discorrer sobre o conceito de currículo e as implicações no cenário escolar, conforme apresentam Sacristán e Perez Gomez (2000), Sacristán (2000, 2013), Moreira e Silva (2000), Moreira (2001) acrescidos de abordagens de autores voltados para a EJA, como Arroyo (2005, 2011) e Oliveira (2007), considerando, também, a documentação oficial para a modalidade: Parecer CNE/CEB Nº11 /2000, os Parâmetros Curriculares Nacionais (BRASIL, 2001; BRASIL, 2002), os Parâmetros Curriculares Municipais da Rede Municipal de Ensino de Santa Maria - RS (SANTA MARIA, 2014b) e Resolução CMESM n 33/2014, que define as diretrizes curriculares para a modalidade de Educação de Jovens e Adultos no Sistema Municipal de Ensino de Santa Maria - RS (SANTA MARIA, 2014a). Ainda destaca-que a Base Nacional Comum Curricular (BNCC), como documento norteador, prioriza as etapas da Educação Básica, sugerindo adaptações nas propostas curriculares para a EJA. (BRASIL, 2017).

Inicialmente, retoma-se o conceito de currículo e contextualiza as implicações no contexto escolar. Na sequência, busca-se levantar elementos subjacentes à identidade curricular da modalidade, logo após, arrolam-se as orientações curriculares para a EJA a partir de documentos em âmbito nacional e municipal e, para encerrar as discussões, evoca-se a proposta de integração da Educação Profissional à modalidade e, nas considerações finais, exploram-se algumas pistas para reflexão e ressignificação do currículo da EJA como espaço de exercício de direitos e de emancipação. 


\section{CONCEITO DE CURRÍCULO E IMPLICAÇÕES NO CONTEXTO ESCOLAR}

Sobre o conceito de currículo, Sacristán e Perez Gomez (2000) resgatam a origem do termo currículo, que advém do latim curriculum, mesma raiz de currere, na acepção de carreira, percurso a ser realizado, retomando a evolução do conceito em diferentes tempos e conjunturas. Para eles, são diversas as concepções de currículos que emergem e o entendimento da multiplicidade de significados existentes requer levar em conta a amplitude variável do significado, o currículo dentro de práticas diversas, a perspectiva dos que aprendem e, por último, o currículo vinculado ao processo ou uma representação dele mesmo (SACRISTÁN; PEREZ GOMEZ, 2000).

No entanto, para compreensão do conceito do currículo como processo, Sacristán e Perez Gomez (2000) destacam obstáculos que dizem respeito a uma concepção burocratizante, uma concepção técnica e política do papel do professor, que é visto como um profissional que está apenas para executar o currículo planejado e, ainda, uma concepção prática do ensino, ou seja, um currículo pautado para o domínio de habilidades concretas. Nesse sentido, é sugerida a necessidade de superação dos referidos obstáculos em direção a um currículo que atenda à pluralidade e complexidade do processo educacional, envolvendo as contradições e os conflitos inerentes ao espaço escolar e sociedade. Para os autores, há dificuldades ao se construir um conceito válido para currículo, mas manifestam que qualquer conceitualização precisa levar em conta as manifestações da cultura que acontece na escola, o currículo, como projeto de um processo histórico e social, como campo de interação de ideias e práticas e a possibilidade de viabilizar a intervenção docente na construção.

Prosseguindo a discussão sobre o currículo escolar, Sacristán (2000) argumenta que este se forma, dimensiona-se e se redimensiona no universo das práticas escolares, com a contribuição de alunos e professores. A relação entre a prática pedagógica e o currículo faz parte da sua constituição desse como processo, expressando recortes seletivos das vivências culturais, sociais e políticas de um determinado contexto, as quais definirão a composição curricular, pressupondo a concretização dos fins sociais e culturais. Portanto,

\footnotetext{
Não podemos esquecer que o currículo supõe a concretização dos fins sociais e culturais, de socialização, que se atribui à educação escolarizada, ou de ajuda ao desenvolvimento, de estímulo, e cenário do mesmo, o reflexo de um modelo educativo determinado, pelo que necessariamente tem de ser um tema controvertido e ideológico, de difícil concretização num modelo ou proposição simples (SACRISTÁN, 2000, p. 15).
}

A qualidade dos processos educativos passa por pensar e repensar a composição curricular centrada numa relação dialógica entre teoria-prática, tendo em vista os sujeitos envolvidos, professores e alunos, na tentativa de aproximação do mundo das experiências aos processos de formação, pois a distância entre um currículo escolar comprometido com os sujeitos e o currículo oferecido ocasiona 
O fracasso escolar, a desmotivação dos alunos, o tipo de relações entre estes e os professores, a disciplina em aula, a igualdade de oportunidades, etc. são preocupações de conteúdo psicopedagógico e social que têm concomitâncias com o currículo que se oferece aos alunos e com o modo como é oferecido. Quando os interesses dos alunos não encontram algum reflexo na cultura escolar, se mostram refratários a esta sob múltiplas reações possíveis: recusa, confronto, desmotivação, fuga, etc. (SACRISTÁN, 2000, p. 30).

Sacristán (2000) salienta a relevância do currículo como elemento propulsor para a qualidade do ensino, compreendendo novas organizações curriculares, pertinência de métodos, a transformação das condições da escola e a formação de professores.

Frente às novas organizações da sociedade atual, Sacristán (2013) reflete sobre a complexidade das discussões sobre currículo, a pluralidade cultural em contraponto à homogeneização curricular, a difusão radicalizada das tecnologias da informação e comunicação, a oferta de oportunidades de formação fora do espaço escolar e a busca constante pela melhoria do currículo. Dessa forma, estamos “condenados à incerteza, ao diálogo e ao pacto", pois não há “consensos fáceis", apenas "propostas provisórias sobre os conflitos culturais que raramente afloram" e as possíveis respostas poderiam ser buscadas por meio "de um processo de diálogo político e social” (SACRISTÁN, 2013, p. 29). O mesmo autor ainda enfatiza que

Esse sempre será um debate vivo, inacabado e evasivo, pois reflete o caráter aberto, plural e dinâmico da sociedade e da cultura, que no plano da educação, exige respostas flexíveis, com diálogo e certa dose de relativismo, ainda que claras. Está muito fixada a ideia de que os conteúdos escolares devem adotar os consensos, deixar de lado os conflitos, isolar-se das polêmicas nas quais seria muito difícil ser neutro [...] (SACRISTAN, 2013, p. 29).

A preocupação com o currículo escolar levou Moreira e Silva (2000) a apresentarem uma abordagem histórica da evolução curricular, destacando que, no século XIX, esse tema ganhou maior importância, desprendendo-se de uma constituição racional, sistemática e tecnicista para uma composição mais complexa e ampla, envolvendo os contextos sociais, com suas manifestações culturais, sociais, ideológicas e políticas. Assim, “[...] o currículo é considerado um artefato social e cultural”. Isso significa que ele é colocado na moldura mais ampla de suas determinações sociais, de sua história, de sua produção contextual (MOREIRA; SILVA, 2000, p. 7).

Os autores apresentam a existência de uma relação intrínseca entre currículo e ideologia, cultura e poder, como três eixos que são temas da Teoria Crítica e da Sociologia do Currículo. Entende-se, assim, que o currículo escolar deveria contemplar esses apontamentos, posicionando-se em favor da construção de uma sociedade mais crítica, ética e democrática.

Considerada dessa forma, a questão curricular rompe os limites tecnicistas para ingressar nos campos sociológico e político, vinculando-se às vivências sociais, subjetividades individuais e coletivas, relações de poder e conflitos de cultura, gênero, sexo, etnia, como destaca Arroyo: 
Assumida esta dimensão: direitos negados historicamente aos mesmos coletivos sociais, raciais, consequentemente teremos de assumir a EJA como uma política afirmativa, como um dever específico da sociedade, do Estado, da pedagogia e da docência para com essa dívida histórica de coletivos sociais concretos (ARROYO, 2005, p. 30).

Portanto, a realidade vivencial dos alunos da EJA, seus desejos, necessidades, bem como a prática, insatisfações e êxitos dos seus professores, precisam ser olhados e fazer parte do currículo dessa modalidade de ensino. Ainda na perspectiva de o currículo ser um espaço de conflitos e lutas, Arroyo assim se manifesta:

Como vimos, o campo do conhecimento sempre foi tenso, dinâmico, aberto à dúvida, à revisão e superação de concepções e teorias contestadas por novas indagações que vêm do real. Quando os currículos se fecham a essa dinâmica do próprio conhecimento terminam presos a conhecimentos superados, passados da data de validade. Quando se abrem às indagações, vivências postas na dinâmica social, se enriquecem, revitalizam. Há tantos conhecimentos vivos pressionando, disputando o território dos currículos (ARROYO, 2011, p. 38).

Diante das exposições, torna-se claro que, quando se discute currículo, ultrapassa-se a concepção restrita que diz respeito apenas à seleção de conteúdos, organização e métodos, atendendo a diretrizes legais para cumprimento de metas e planejamentos de políticas públicas educacionais. A organização curricular precisa atender à complexidade e à dinamicidade do mundo atual, que requer constante atualização, diálogo entre os envolvidos, para que conhecimentos de interesse dos educandos, que favoreçam a compreensão histórica da sociedade e abram espaço para debates dos conflitos sociais, componham o currículo escolar.

Valendo-se do questionamento sobre o papel dos educadores na definição dos currículos escolares, Arroyo (2011, p. 34) indaga se devemos continuar contando nossa história para nós mesmos, os profissionais do conhecimento e da educação, e se há lugar para nossas autorias no território do currículo para a educação básica. Poderíamos também então perguntar: "Há lugar para nossas autorias (professores) no território do currículo para a Educação de Jovens e Adultos?” Os professores têm um papel decisivo na elaboração do currículo escolar, pois são os responsáveis finais em transformar diretrizes curriculares educacionais em práticas pedagógicas que produzam aprendizagens significativas.

Ignorar ou colocar em segundo plano as vivências sociais dos estudantes e as práticas pedagógicas dos professores da EJA pode significar um grande comprometimento dos processos de construção do conhecimento dessa modalidade, pois "um conteúdo passa a ser valioso e legítimo quando goza do aval social dos que têm poder para determinar sua validade; por isso a fonte do currículo é a cultura que emana de uma sociedade" (SACRISTÁN, 2000, p. 155).

Nesse sentido, Vasconcelos (2009) confirma a necessidade avançar na concretização de um currículo que torne a escola um espaço de aprendizagem significativa e duradoura e que contribua para o desenvolvimento humano dos seus sujeitos, viabilizando a construção dos saberes primordiais para a formação dos educandos. 


\section{ORIENTAÇÕES CURRICULARES PARA A EDUCAÇÃO DE JOVENS E ADULTOS}

Voltando-se para as orientações curriculares para a EJA, o Parecer CNE/CEB No 11/200 (BRASIL, 2000) estabeleceu as diretrizes curriculares para a modalidade, atendo-se em ressaltar a de viabilização de um modelo pedagógico próprio, com situações pedagógicas diferenciadas para a satisfação das necessidades de aprendizagem de jovens e adultos, bem como a observância dos princípios da contextualização, do reconhecimento de identidades pessoais e das diversidades coletivas, flexibilidade quanto à organização curricular e valorização das múltiplas experiências de trabalho, de vida e da situação social dos estudantes (BRASIL, 2000).

A Proposta Curricular para o Primeiro Segmento da EJA refere-se à alfabetização e pós-alfabetização de jovens e adultos (BRASIL, 2001), sendo currículo posto como um espaço de expressão das concepções de pessoa, sociedade e necessidades educativas.

\footnotetext{
Qualquer projeto de educação fundamental orienta-se, implícita ou explicitamente, por concepções sobre o tipo de pessoa e de sociedade que se considera desejável, por julgamentos sobre quais elementos da cultura são mais valiosos e essenciais. O currículo é o lugar onde esses princípios gerais devem ser explicitados e sintetizados em objetivos que orientem a ação educativa. Nos fundamentos desta proposta, delineia-se uma visão bastante geral da situação social que vivemos hoje, das necessidades educativas dos jovens e adultos pouco escolarizados, do papel da escola e do educador (BRASIL, 2001a, p. 15).
}

Já a Proposta Curricular para o Segundo Segmento da EJA versa sobre os anos finais do Ensino Fundamental (BRASIL, 2002), destacando os elementos que devem ser observados em favor da especificidade da modalidade, como a valorização dos conhecimentos, os interesses e as necessidades de aprendizagem dos alunos e a organização de propostas flexíveis que abarquem diversidade de temas. Quanto às diretrizes curriculares para a Educação de Jovens e Adultos/Ensino Médio, não há publicação de documentos por parte do Ministério e Educação. Nesse sentido, o documento afirma que "os objetivos educacionais são os mesmos do Ensino Fundamental e/ou Médio frequentado por alunos entre 7 e 17 anos" (BRASIL, 2002, p. 87).

Os dois documentos em questão apresentam três eixos articuladores para o currículo: o tempo, a cultura e o trabalho. Ao abordar cultura, trata-se da amplitude de vivências pessoais e sociais e os significados construídos que se espelham na constituição de vida dos educandos, que na EJA se identificam com a necessidade de preparar para o trabalho. Inclusive muitos jovens e adultos já trabalham, até mesmo na informalidade, ou expressam a vontade e emergência em exercer uma atividade remunerada, tornando-se a formação para o trabalho um objetivo contundente. A organização da modalidade abre espaço para disposições diferenciadas do tempo escolar, amparada na flexibilização e possível adequação às necessidades dos educandos.

Somente em 2010, por meio do Parecer CNE/CEB Nº 7/2010, que trata das Diretrizes Curriculares Nacionais Gerais para a Educação Básica, as orientações curriculares para Educação de Jovens 
e Adultos foram retocadas, de forma sucinta, enfatizando a necessidade de flexibilização do tempo, do espaço e do currículo, dando abertura para organização de percursos individualizados, conforme necessidades de aprendizagens. Sugere o desenvolvimento de competências para o trabalho, articulação com a oferta de Educação Profissional integrada à EJA e formação continuada específica para os professores (BRASIL, 2010).

No âmbito local, a implementação da EJA ocorreu em 2001 na Rede Municipal de Ensino de Santa Maria - RS, mas foi normatizada apenas em 2014 pela Resolução nº 33/2014, do Conselho Municipal de Educação de Santa Maria (CMESM).

Sobre a proposta curricular da Educação de Jovens e Adultos na Rede Municipal de Ensino do Município de Santa Maria/RS, o CMESM determinou:

Art. 23. O Sistema Municipal de Ensino deverá adequar a sua proposta curricular para atender às necessidades de aprendizagem dos estudantes da Educação de Jovens e Adultos (SANTA MARIA, 2014a, s/p).

Em atendimento às determinações do CMESM, a Secretaria de Município da Educação de Santa Maria promoveu a elaboração dos Parâmetros Curriculares Municipais (PCM) para a Educação de Jovens e Adultos, no ano de 2014, com a participação dos professores da modalidade.

\footnotetext{
Na elaboração desta proposta, optou-se por manter um olhar que segue a lógica disciplinar de organização da educação escolar de Ensino Fundamental, assumindo que, não obstante suas limitações conhecidas é a forma como os professores e os alunos percebem a organização do conhecimento e a aprendizagem. Contudo, recomenda-se que a prática pedagógica avance em direção à proposta de trabalho interdisciplinar e contextualizada, que busque incorporar conteúdos que estão além de cada disciplina e são importantes à vida do jovem e do adulto, como as questões de identidade e expressão cultural; sociedade, ambiente e desenvolvimento; participação e política; sexualidade, etc. (SANTA MARIA, 2014b, s/p).
}

Como resultado final, os Parâmetros Curriculares Municipais repõem os princípios norteadores dos marcos legais da EJA, mas mantêm uma organização curricular semelhante à educação regular No entanto, mesmo assim, o documento se desenha como uma tentativa de construção da especificidade curricular da modalidade na Rede Municipal de Ensino de Santa Maria.

Recentemente, a publicação da Base Nacional Comum Curricular (BNCC) (BRASIL, 2017) foi motivo de críticas por parte por professores e pesquisadores da EJA porque o documento não apresenta orientações específicas para a modalidade, além de não ter tido a participação de representantes da modalidade na elaboração do texto. O documento BNCC sugere que as orientações para a Educação Básica sejam observadas pelas demais modalidades.

Essas decisões precisam, igualmente, ser consideradas na organização de currículos e propostas adequados às diferentes modalidades de ensino (Educação Especial, Educação de Jovens e Adultos, Educação do Campo, Educação Escolar Indígena, Educação Escolar Quilombola, Educação a Distância), atendendo-se às orientações das Diretrizes Curriculares Nacionais (BRASIL, 2017, p. 17). 
Na verdade, a BNCC deveria ter aberto espaço para a EJA e suas especificidades, pois os últimos documentos nacionais sobre diretrizes curriculares específicas para a EJA datam de 2001 e 2002, carecendo as referidas diretrizes, no mínimo, de revisão e atualização.

Nessa perspectiva, Arroyo (2005, p. 19) alega que a EJA “é um campo ainda não consolidado nas áreas de pesquisa, de políticas públicas e diretrizes educacionais, da formação de educadores e intervenções pedagógicas", mas com tentativas de configurar sua especificidade, o que inclui debates sobre o currículo, a valorização de saberes e experiências dos educandos e as inferências dos professores.

Refletir sobre o currículo na EJA é compreender as dificuldades que as atuais configurações curriculares manifestam, como "propostas e práticas curriculares infantilizantes e formalistas" e visualizar os avanços, pois "muito já existe em nossas escolas e classes que ajuda a ter uma visão otimista das possibilidades de enfrentamento dos problemas" (OLIVEIRA, 2007, p. 99). Como não se pretende encerrar as discussões e nem propor respostas acabadas, as reflexões seguem sobre quais conhecimentos seriam necessários e importantes para jovens e adultos que buscam na escola sua escolarização. Para Oliveira (2007, p. 98), “A resposta poderia ser a de que os conteúdos necessários são aqueles que podem ser utilizados na vida cotidiana como meio para a autonomia do sujeito".

\section{A BUSCA POR UMA IDENTIDADE CURRICULAR}

Partindo do entendimento de que currículo é um processo de construção social, que expressa diferentes significados de acordo com as mudanças sociais num dado tempo e espaço, como manifestação de ideologia, cultura e poder (MOREIRA; SILVA, 2000), emerge a relação entre currículo e identidade. Assim, o currículo se assenta em um campo carregado de diferentes identidades e ideologias de acordo com os interesses dos grupos de pertencimento ou dominante, sendo propício questionar sua constituição:

O currículo é visto como território em que ocorrem disputas culturais, em que se travam lutas entre diferentes significados do indivíduo, do mundo e da sociedade, no processo de formação de identidades. Essa constatação levanta, inevitavelmente, algumas questões. Que identidades os atuais currículos estão ajudando a produzir? Que identidades deveriam produzir? Identidades em sintonia com padrões dominantes ou identidades plurais? Identidades comprometidas com o arranjo social existente ou identidades questionadoras e críticas? (MOREIRA, 2001, p. 5).

Quando da institucionalização da EJA no país, destacando-se os marcos legais - Constituição Federal (BRASIL, 1988), LDBEN nº 9394/96 (BRASIL, 1996), Parecer CNE/CEB n 11/2000 (BRASIL, 2000) e as Diretrizes Curriculares Nacionais para a modalidade (BRASIL, 2001 e 2002) afirmações sobre a sua identidade foram apontadas:

No entanto, há especificidades marcantes que precisam ser identificadas, particularmente quando a tarefa é construir uma proposta curricular. Determinar claramente a identidade de um curso de EJA pressupõe um olhar diferenciado para seu público, acolhendo de fato seus 
conhecimentos, interesses e necessidades de aprendizagem. Pressupõe também a formulação de propostas flexíveis e adaptáveis às diferentes realidades, contemplando temas como cultura e sua diversidade, relações sociais, necessidades dos alunos e da comunidade, meio ambiente, cidadania, trabalho e exercício da autonomia (BRASIL, 2002, p. 87).

Pela orientação oficial, a identidade de um curso de EJA ampara-se num olhar diferenciado, que se relaciona a conhecimentos, interesses, necessidades de aprendizagens e propostas flexíveis conforme a realidade dos educandos. Na sequência do mesmo documento, a referência à identidade da EJA abrange a mudança do paradigma compensatório para uma evolução ao paradigma emancipatório:

A identidade da EJA vem sendo construída e modificada ao longo dos últimos anos. Anteriormente a denominação "supletivo" embutia a conotação de compensar "o tempo perdido" ou "complementar o inacabado", com a ideia de substituir de forma compensatória o ensino regular. O que hoje é concebido como educação de jovens e adultos corresponde a aprendizagem e qualificação permanentes - não suplementares, mas fundamentais e que favoreçam a emancipação (BRASIL, 2002, p. 87).

$\mathrm{Na}$ esfera local, o CMESM orientou que a proposta municipal deveria atender à identidade própria da EJA, levando em conta os perfis dos alunos, como segue:

Art. 24. A Secretaria de Município da Educação deverá adotar providências em relação à adequação da proposta curricular, de modo que esta atenda à identidade própria da Educação de Jovens e Adultos, considerando os perfis dos estudantes, as faixas etárias, pautando-se nos princípios de equidade, diferença e proporcionalidade na apropriação e contextualização das diretrizes curriculares nacionais e na proposição de um modelo pedagógico próprio (SANTA MARIA, 2014a, s/p).

No entanto, esse olhar diferenciado ou observância à identidade própria pouco repercutiram como um ingrediente constituinte para a construção da identidade da modalidade que carrega ainda o paradigma compensatório de reposição de conteúdos, oriundo da visão do Ensino Supletivo, voltado para um universo de relativa homogeneidade cultural pela condição dos estudantes serem analfabetos migrantes rurais e trabalhadores de baixa qualificação, como afirma Di Pierro (2005), ao discorrer sobre a identidade e as políticas públicas da EJA no Brasil. Porém, a ideia de que a EJA caracteriza-se por “[...] demandas particulares e que atende uma população que, além de historicamente excluída, é marcada pela diversidade e cruzada por múltiplas tensões, amplia-se na sociedade brasileira" (PAIVA; SALES, 2013, p. 5), sinalizando para um

[...] movimento inconcluso de redefinição da identidade da educação de jovens e adultos no Brasil desencadeado pela transição de paradigmas político-pedagógicos e pela percepção da diversidade sociocultural dos sujeitos de aprendizagem (DI PIERRO, 2005, p. 1116).

Desta forma, esse movimento em direção à compreensão da diversidade de sujeitos que compõem a EJA em superação à ideia de homogeneidade deve contribuir para a composição de 
um currículo que atenda as suas expectativas de aprendizagem, "identidades singulares- de classe, geracionais, de gênero, étnicas, culturais ou territoriais" (DI PIERRO, 2005).

Santos e Pereira (2017), em suas reflexões sobre o currículo da EJA, delineiam a existência de três abordagens curriculares, descortinando a nebulosidade existente sobre a identidade da modalidade. A primeira abordagem é pautada pelos ideais de Educação Popular, valorizando as vivências e conhecimentos dos estudantes envolvidos, com vistas à transformação social; a segunda abordagem tem cunho propedêutico, em aproximação ao currículo da Educação Básica, com algumas adaptações ao perfil do público e à organização da modalidade; a terceira abordagem privilegia o enfoque direcionado para a formação profissional.

Salienta-se a interdependência entre currículo e identidade para a construção de uma proposta curricular destinada à EJA, que deve estar intrinsicamente ligada aos espaços coletivos e culturais seus sujeitos.

O currículo é lugar, espaço, território. O currículo é relação de poder. O currículo é trajetória, viagem, percurso. O currículo é autobiografia, nossa autobiografia, nossa vida, curriculum vitae: no currículo se forja nossa identidade. $\mathrm{O}$ currículo é texto, discurso documento. $\mathrm{O}$ currículo é documento de identidade (SILVA, 2002, p. 150).

As discussões e reflexões sobre identidade curricular da EJA são pertinentes e indispensáveis no sentido de tornar o ensino para os jovens e adultos mais significativo e de qualidade e também como condição de enfrentamento das fragilidades existentes que se expressam em evasão, redução das matrículas e crescente invisibilidade.

\section{EDUCAÇÃO PROFISSIONAL INTEGRADA À EDUCAÇÃO DE JOVENS E ADULTOS}

A integração entre a Educação Básica e a Educação Profissional na modalidade Educação de Jovens e Adultos está regrada pela Lei No 11.741/2008 (BRASIL, 2008) e se constitui uma meta do Plano Nacional de Educação 2014-2024 (BRASIL, 2014), com a expectativa de que, pelo menos 25\% da oferta da matrícula de EJA, esteja integrada à Educação Profissional.

A Educação Profissional pode ser viabilizada por meio da oferta de formação inicial e continuada ou qualificação profissional, de educação profissional técnica de nível médio e de educação profissional tecnológica de graduação e pós-graduação (BRASIL, 2008). A afluência da Educação Profissional sobre a modalidade EJA tem suscitado discussões a respeito do redimensionamento do currículo, das possibilidades de se efetivar uma formação de qualidade, pois, além da questão curricular, envolve a formação de professores, carga horária, infraestrutura adequada e recursos financeiros.

Como o foco da presente pesquisa é a modalidade EJA/Ensino Fundamental da Rede Municipal de Santa Maria, serão levantadas algumas considerações sobre a construção de uma proposta curricular de EJA integrada à formação profissional inicial e continuada dos estudantes. Nesse prisma, 
Ciavatta e Rummert (2010, p. 476) afirmam que "O currículo constitui uma elaboração complexa que incorpora as mais diversas dimensões das relações sociais subjacentes aos processos produtivos, à cultura, ao conhecimento e à organização do espaço-tempo da escola".

Ciavatta e Rummert (2010), ao se referirem à organização curricular da EJA, voltada para estudantes trabalhadores, apresentam três pressupostos que estruturam o currículo. O primeiro pressuposto considera que as relações pedagógicas expressam as correlações de força e poder de uma dada sociedade. $\mathrm{O}$ segundo pressuposto diz respeito à organização curricular, a qual é determinada por escolhas advindas de critérios sócio-políticos que, por sua vez, definem a metodologia e os conteúdos. O terceiro pressuposto destaca que a elaboração de uma proposta curricular não poderia ser construída sem a participação dos sujeitos envolvidos, os contextos históricos e políticos em que estes se situam e as relações com as conjunturas sócio-políticas mais amplas. Para as autoras, "As categorias cultura, trabalho, controle social, poder, hegemonia e ideologia constituem elementos fundamentais para explicitar essas relações na perspectiva de ruptura com as ações pedagógicas conservadoras" (CIAVATTA; RUMMERT, 2010, p. 468). Diante disso, as considerações aqui abordadas poderão servir de subsídios para entendimento da complexidade de fatores que envolvem a elaboração de uma proposta curricular, em um movimento dialético com os envolvidos: sujeitos e contextos.

Por conseguinte, o currículo escolar deve abrir espaço para a inserção de jovens e adultos no mundo do trabalho, como alternativa de superação das desigualdades sociais. As autoras enfatizam que,

No mundo atual, o currículo escolar é uma peça importante para a participação de jovens e adultos nesse universo valorizado da ciência, da tecnologia e da cultura. O trabalho é a mediação fundamental do processo que se desdobra na contradição entre capital e trabalho, na divisão técnica e social do trabalho, na formação das classes sociais e em suas lutas pela superação das desigualdades (CIAVATTA; RUMMERT, 2010, p. 475-476).

A oferta da EJA integrada à Educação Profissional não pode ser pensada privilegiando a qualificação para o trabalho em detrimento da formação básica. Para Ramos (2010, p. 81), o desafio reside na construção de um currículo capaz de integrar os conhecimentos gerais e os específicos da Educação Profissional:

Sob o enfoque pedagógico, finalmente, a forma integrada de oferta da educação básica com a educação profissional obedece a algumas diretrizes ético-políticas, que agora reiteramos. Integra conhecimentos gerais e específicos, proporcionando a construção do conhecimento pela mediação do trabalho, da ciência e da cultura. Orienta-se pela utopia de superar a dominação dos trabalhadores formando-os como dirigentes pela mediação do conhecimento.

Na perspectiva de integração da EJA à Educação Profissional, o trabalho solidifica-se como eixo articulador do currículo. No entanto não se pode correr o risco de reduzir um currículo de formação profissional às necessidades de mercado, render-se a processos de qualificação aligeirados, norteados 
pela lógica capitalista de formação de mão de obra como objetos e não sujeitos de um sistema de produção. Nesse sentido,

[...] não se pode admitir que a educação profissional seja planejada e desenvolvida para atender às necessidades identificadas no mercado de trabalho, tendo em vista, antes de tudo, os interesses da produção e, só depois, os interesses dos trabalhadores. Essa abordagem coloca os trabalhadores como objetos da produção e do mercado de trabalho, contrariamente ao compromisso ético-político de se resgatar a centralidade dos sujeitos no processo educativo (RAMOS, 2008, p. 77).

Prosseguindo nessa linha de pensamento, Ramos (2010, p. 77) frisa que os estudantes da EJA, como sujeitos concretos, "têm o direito de se apropriar dos conhecimentos produzidos pela humanidade e produzir cultura, no sentido não de se adequarem à realidade dada, mas de compreendê-la, apropriar-se de seus potenciais e transformá-la". A autora acrescenta que

[...] formar profissionalmente não seria preparar exclusivamente para o exercício do trabalho, mas proporcionar a compreensão das dinâmicas sócio-produtivas das sociedades modernas, com as suas conquistas e os seus revezes, e também habilitar as pessoas para o exercício produtivo, autônomo e crítico de profissões, não se esgotando nelas (RAMOS, 2010, p. 78).

O acesso à educação é um direito humano e, por extensão, à EJA e à Educação Profissional, por isso "[...] não seria justo que aqueles aos quais o direito à educação básica foi negado, tivessem que esperar a reparação deste para só depois buscar a educação profissional” (RAMOS, 2010, p. 77).

Para além dos fatores individuais, a análise dos fatores intraescolares e, entre eles, o currículo é uma dimensão que precisa considerar, no plano federal, estadual e municipal, a dimensão humana da população que se efetiva como estudante da EJA no Brasil e apresentar-se como uma alternativa contundente de dirimir a exclusão social e extremar a concretude de exercício de direitos.

\section{CONSIDERAÇÕES FINAIS}

As diretrizes curriculares nacionais e municipais orientam para atentar à identidade social e individual dos estudantes e alertam para o fato de que as aprendizagens devem ser constituídas pelas interações dos processos cognitivo, afetivo, sociocultural, decorrentes das relações entre as diferentes identidades dos diversos sujeitos do contexto escolar e pelas interrelações entre o tempo, a cultura e o trabalho. Porém, há uma distância entre as orientações teóricas oficiais, o currículo das escolas de EJA e as trajetórias de vida de jovens e adultos com diferentes identidades (de classe, gênero, raça e etária), acrescidas de vivências sociais e culturais em contextos distintos.

Para aproximação dessa distância, propõe-se o reconhecimento da diversidade dos estudantes, de suas necessidades e das condições de aprendizagem, os processos de escolarização por percursos formativos individualizados, com flexibilidade de tempo, maior integração dos saberes cotidianos 
e os saberes escolares e o diálogo permanente do universo escolar com a realidade, com o mundo em permanente processo de instabilidade e mudanças. Não sendo assim, a EJA pode se restringir a uma oferta de escolaridade com vistas à certificação tão necessária na sociedade atual para a continuidade dos estudos, a qualificação profissional e a consequente inserção ou permanência no emprego. Para tal e de fato, o debate precisa se ampliar, passando pela formação dos professores, pela abordagem metodológica, avaliação, pelas condições das escolas públicas que pouco oferecem aos estudantes em ternos de infraestrutura e aparato tecnológico, atravancando em muito a viabilização de ensino de qualidade.

Pelo exposto, aponta-se para a necessidade em ressignificar as políticas públicas educacionais para EJA para superação da atual conjuntura educacional extremamente fragilizada, na busca por uma escola pública de melhor qualidade, em cujos espaços haja a apropriação dos conhecimentos sistematizados, o fomento do desenvolvimento científico, a promoção da equidade e da inclusão social, o respeito às diferenças, a valorização da diversidade e vivências pautadas pelos princípios democráticos. Acredita-se que discutir o currículo escolar da EJA, com a contribuição de alunos e professores, é uma etapa desse processo em direção à solidificação da modalidade como espaço de exercício de direitos e de emancipação.

\section{REFERÊNCIAS}

ARROYO, M. Educação de jovens-adultos: um campo de direitos e de responsabilidade pública. In: SOARES, L.; GIOVANETTI, M. A. G. de Castro; GOMES, N. L. (org.). Diálogos na educação de jovens e Adultos. Belo Horizonte: Autêntica, 2005. p. 19-50.

ARROYO, M. Currículo, território em disputa. Petrópolis: Vozes, 2011.

BRASIL. Base Nacional Comum Curricular. Brasília: MEC, 2017. Disponível em: https://bit.ly/ 3jaQY0F. Acesso em: 22 dez. 2019.

BRASIL. Conselho Nacional de Educação. Parecer CNE/CEB n ${ }^{\circ}$ 11/2000, de 10 de maio de 2000. Institui as Diretrizes Curriculares Nacionais para a Educação de Jovens e Adultos. Diário Oficial da União, Brasília, DF, 9 jun. 2000a, Seção 1, p. 15.

BRASIL. Conselho Nacional de Educação. Parecer CNE/CEB nº 7/2010, aprovado em 7 de abril de 2010. Diretrizes Curriculares Nacionais Gerais para a Educação Básica. Brasília: CNE, 2010. Disponível em: https://bit.ly/2EKeP8q. Acesso em: 28 dez. 2019. 
BRASIL. Constituição do Brasil de 1988. Brasília: Presidência da República, 1988. Disponível em: https://bit.ly/3jf7iNY. Acesso em: 22 dez. 2019.

BRASIL. Lei $\mathbf{N}^{\mathbf{0}}$ 11.741, de 16 de julho de 2008. Altera dispositivos da Lei $\mathrm{n}^{\circ}$ 9.394, de 20 de dezembro de 1996. Estabelece as diretrizes e bases da educação nacional, para redimensionar, institucionalizar e integrar as ações da educação profissional técnica de nível médio, da educação de jovens e adultos e da educação profissional e tecnológica. Brasília, 2008. Disponível em: https://bit. ly/3jcz0uE. Acesso em: 10 nov. 2019.

BRASIL. Ministério da Educação. Lei de Diretrizes e Bases da Educação Nacional no 9394/96, de 20 de dezembro de 1996. Estabelece as diretrizes e bases da educação nacional. Brasília: MEC, 1996b. Disponível em: https://bit.ly/3kRLU1B. Acesso em: 30 dez. 2019.

BRASIL. Ministério da Educação. Proposta Curricular para a Educação de Jovens e Adultos: primeiro segmento do ensino fundamental. Secretaria de Educação Fundamental. Brasília: MEC, 2001. Disponível em: https://bit.ly/3kWc5UN. Acesso em: 8 dez. 2019.

BRASIL. Ministério da Educação. Proposta Curricular para a Educação de Jovens e Adultos: segundo segmento do ensino fundamental: $5^{\mathrm{a}}$ a $8^{\mathrm{a}}$ série. Secretaria de Educação Fundamental. Brasília: MEC, 2002. Disponível em: https://bit.ly/2S8DFBK. Acesso em: 8 dez. 2019.

BRASIL. Plano Nacional de Educação. Lei n⿳ 13.005, de 14 de julho de 2014. Aprova o Plano Nacional de Educação e dá outras providências. Brasília, DF: Presidência da República, 2014b. Disponível em: https://bit.ly/3cFBNtQ. Acesso em: 10 out. 2019.

CiAVATTA, M.; RUMMERT, S. M. As Implicações Políticas e Pedagógicas do Currículo na Educação de Jovens e Adultos Integrada à Formação Profissional. Educação \& Sociedade, v. 31 , n. 111, p. 461-480, 2010. Disponível em: https://www.cedes.unicamp.br. Acesso em: 30 jun. 2019.

DI PIERRO, M. C. Notas sobre a redefinição da identidade e das políticas públicas de educação de jovens e adultos no Brasil. Educação \& Sociedade, v. 26, n. 92, p. 1115-1139, 2005.

DOURADO, L.F. Políticas e gestão da educação básica no Brasil: limites e perspectivas. In: Educ. Soc., Campinas, vol. 28, n. 100 - Especial, p. 921-946, out. 2007. Disponível em: http://www.cedes. unicamp.br. Acesso em 26 dez. 2019. 
GIL, A. C. Como elaborar projetos de pesquisa. 6. ed. São Paulo: Atlas, 2017.

HOFLING, E.M. Estado e políticas (públicas) sociais. In: Caderno CEDES [on line]. 2001, v. 21, n. 55, p. 30-41. Disponível em: http://dx.doi.org/10.1590/S0101-32622001000300003. Acesso em: 09 jan. 2020.

MAINARDES, J. Abordagem do ciclo de políticas: uma contribuição para a análise de políticas educacionais, In: Educação \& Sociedade, Campinas, v. 27, n. 94, p. 47-69, jan./abr. 2006. Disponível em: http://www.cedes.unicamp. br. Acesso em 26 dez. 2019.

MOREIRA, A. F.B; SILVA, T. T. (org.). Currículo, Cultura e Sociedade. 4. ed. São Paulo, Cortez, 2000.

MOREIRA, A. F.B. Currículo, cultura e formação de Professores. In: Educar, n. 17, p. 39-52. Curitiba, 2001. Disponível em: http://dx.doi.org/10.1590/0104-4060.218. Acesso em: 09 jan. 2020

OLIVEIRA, I. B. Reflexões acerca da organização curricular e das práticas pedagógicas na EJA. Educar em revista [online], n. 29, p. 83-100, 2007.

PAIVA, J. ; SALES, S. Contextos, perguntas, respostas: o que há de novo na educação de jovens e adultos? In: Arquivos Analíticos de Políticas Educativas, n.69, v.21, p. 1-14, set. 2013.

RAMOS, M. N. Implicações Políticas e Pedagógicas da EJA integrada à Educação Profissional. In: Educação e Realidade, v. 35, n.1, p. 65-85, 2010. Disponível em: https://bit.ly/3kTWCV7. Acesso em: 19 jul. 2019.

SACRISTÁN, J. G.; PEREZ GOMEZ, A. I. Compreender e transformar o ensino. Porto Alegre: Artmed, 2000.

SACRISTÁN, J. G. O currículo: uma reflexão sobre a prática. 3. ed. Porto Alegre: Artmed, 2000.

SACRISTÁN, J. G. (org.). Saberes e incertezas sobre o currículo. Porto Alegre: Penso, 2013.

SANTA MARIA. Conselho Municipal de Educação. Resolução no 33/2014. Define Diretrizes Curriculares para a modalidade de Educação de Jovens e Adultos no Sistema Municipal de Ensino de Santa Maria, RS, 2014a. 
SANTA MARIA. Secretaria de Município da Educação. Parâmetros Curriculares Municipais para Educação de Jovens e Adultos, Santa Maria: SMEd, 2014b.

SANTOS, J. S.; PEREIRA, M. V. Educação de Jovens e Adultos: um currículo que demanda mais atenção. In: EDUCERE XIII CONGRESSO NACIONAL DE EDUCAÇÃO: FORMAÇÃO DE PROFESSORES: CONTEXTOS, SENTIDOS E PRÁTICAS, 2017, Curitiba. Curitiba Anais [...]. Curitiba: PUCPR, 2017. p. 1-15.

VASCONCELLOS, C. Currículo: a atividade humana como princípio educativo. São Paulo: Cadernos Pedagógicos do Libertad, v. 7. Libertad, 2009. 
